\title{
Psychological Stress-Derived Prolactin Modulates Occludin Expression in Vaginal Epithelial Cells to Compromise Barrier Function
}

\author{
Xueyan Li Xiaowei Liu Song Yu \\ Department of Obstetrics and Gynecology; Beijing Obstetrics and Gynecology Hospital; The Capital \\ Medical University; Beijing, China
}

\section{Key Words}

Epithelial barrier • Psychological stress $\bullet$ Prolactin • Biological transport • T84 cells

\begin{abstract}
Background/Aims: The causative factors of the vaginitis are not fully understood yet. Epithelial barrier dysfunction plays a critical role in the pathogenesis of vaginitis. This study aims to investigate the role of prolactin (PRL) in the causing the vaginal epithelial barrier dysfunction. Methods: Adult rats were treated with water-avoid-stress. The serum levels of PRL were determined by ELISA. T84 cell (T84 cells; a vaginal epithelial cell line) monolayers were prepared to be used assessing the epithelial barrier functions. The expression of occludin in T84 cells was assessed by Chromatin immunoprecipitation assay, methylation specific $P C R$, real time quantitative RT-PCR and Western blotting. Results: The results showed that psychological stress markedly increased the serum levels of PRL in the rat vaginal epithelia. Exposure of T84 cells to PRL in the culture markedly increased the phosphorylation of STAT3 and suppressed the expression of occludin in the cells; the transepithelial electric resistance was decreased and the permeability to a macromolecular tracer was increased in the T84 monolayers, which was mimicked by blocking STAT3, or abolished by over expression of occludin in the epithelial cells. Conclusions: Psychological stress-derived PRL induces vaginal epithelial barrier dysfunction by inhibiting the expression of occludin.
\end{abstract}

Copyright (c) 2015 S. Karger AG, Basel

\section{Introduction}

A thin epithelial layer covers the surface of the mucosa of the internal body cavities, including the airway, gastro intestine, and urogenital tract. The epithelial cells are connected each other by the tight junctions. The cell bodies and the tight junctions form the epithelial barrier that allows water and some substance of small molecular weight to pass through, and

Dr. Song Yu

KARGER 125
Department of Obstetrics and Gynecology; Beijing Obstetrics and Gynecology Hospital; The Capital Medical University; Beijing 100026 (China)

E-Mail yursong@outlook.com 


\section{Cellular Physiology Cell Physiol Biochem 2015;37:153-161 \begin{tabular}{l|l} 
and Biochemistry Published online: August 17, 2015 & $\begin{array}{l}\text { C) 2015 S. Karger AG, Basel } \\
\text { www.karger.com/cpb }\end{array}$ \\
\hline
\end{tabular} \\ Li/Liu/Yu: PRL Compromises Vaginal Epithelial Barrier Function}

restricts substance with large molecular weight to enter the deep region of the mucosa [1]. The epithelial barrier integrity plays a critical role in the maintenance of the homeostasis in the vaginal mucosa [2]. Disruption of the epithelial barrier integrity is associated with the pathogenesis of a large number of mucosal diseases, including allergic airway diseases (such as allergic rhinitis, asthma) [3], chronic intestinal inflammation (such as inflammatory bowel disease) [4], and chronic urogenital inflammation (such as chronic vaginitis) [5]. Yet, the causative factors inducing the epithelial barrier disruption are not fully understood.

The tight junction consists of a number of proteins; the major types are the claudins and the occludins $[6,7]$. The abnormality of any tight junction associated proteins may result in the disruption of tight junction integrity and initiate disorders in the mucosa [8]. Although the studies in epithelial barrier function are advanced rapidly in the recent years [9], the pathogenesis of epithelial barrier dysfunction is to be further investigated.

Prolactin (PRL), also known as luteotropic hormone or luteotropin, is a protein that in humans is best known for its role in enabling females to produce milk; however, it is influential over a large number of functions with over 300 separate actions of PRL having been reported in various vertebrates [10]. Prolactin is secreted from the pituitary gland in response to eating, mating, estrogen treatment, ovulation, and nursing. Prolactin is secreted in a pulsatile fashion in between these events. Prolactin also plays an essential role in metabolism, regulation of the immune system, and pancreatic development. Treating with PRL can alter the histological structure of vaginal mucosa [11]. Whether PRL affect the vaginal epithelial barrier function is unclear.

Psychological stress (stress, in short) is a form of mental response to external or internal stimuli. Upon the stimulation, the central nervous system releases a number of factors (such as corticotrophin releasing factor, prolactin) to adjust certain body activities to avoid being damaged [12]. However, some individuals respond the stimuli inappropriately; release too much stress-associated factors, such as corticotrophin releasing factor or prolactin, which result in inappropriate adjustment of the body activities and induce diseases [12]. It is reported that vaginal hypersensitivity and hypothalamic-pituitary-adrenal axis dysfunction can be induced by neonatal maternal separation in female mice [13]. Recent reports indicate that stress can induce over-release of prolactin (PRL) and induce intestinal mucosal inflammation [12]. Based on the above information, we hypothesize that stress induced PRL-release may induce vaginal epithelial barrier disruption. Thus, we carried out an experimental study. The results showed that stress increased the PRL levels in the vaginal mucosa, induced vaginal epithelial barrier dysfunction via down regulating the expression of occludin.

\section{Materials and Methods}

Reagents

The chromatin immunoprecipitation kit, dextran, cabergoline, spermidine and prolactin were purchased from Sigma Aldrich (Shanghai, China). The PRL ELISA kit was purchased from Guidechem (Shanghai, China). The antibodies of PRL (H-12), occluding (F-7), STAT3 (C-20) and pSTAT3 (B-7) were purchased from Santa Cruz (Shanghai, China). The reagents for real time RT-PCR and Western blotting were purchased from Invitrogen (Shanghai, China).

\section{Rats}

Adult female Wistar Kyoto rats weighing between 450 and 500 g were purchased from Beijing Experimental Animal Center and housed under controlled light-dark conditions (lights on 7 am to 7 pm). The room temperature was adjusted to $23^{\circ} \mathrm{C}-24^{\circ} \mathrm{C}$. Rats were allowed to access freely to food and water. The experimental procedures were approved by the Animal Ethic Committee at the Beijing Obstetrics and Gynecology Hospital. The procedures were performed in accordance with the guidelines.

Determining rat estrous cycle

Following published data [14], the stage of the estrous cycle was determined from the cell types observed on the smears. Vaginal smears were taken daily from all female rats. The vaginal wall of each rat was 


\section{Cellular Physiology Cell Physiol Biochem 2015;37:153-161 \begin{tabular}{l|l|l|}
\hline DOI: 10.1159/000430341 & O 2015 S. Karger AG, Basel
\end{tabular} and Biochemistry Published online: August 17, 2015 www.karger.com/cpb \\ Li/Liu/Yu: PRL Compromises Vaginal Epithelial Barrier Function}

scraped gently using a sterile swab soaked with saline. Epithelial cells on the swab were smeared on a glass slide. The smears were air-dried and stained with $0.1 \%$ methylene blue and observed under a light microscope to determine the estrous cycle. The experiments were performed on the estrus stage.

Stress model

Following reported procedures [15], during non-menstrual period, rats were treated with the water avoided stress. Briefly, the rats were placed on a platform $(10 \mathrm{~cm}$ in diameter) surrounded with water $(5$ $\mathrm{cm}$ above water) in a container ( $40 \mathrm{~cm}$ in diameter and $80 \mathrm{~cm}$ in height) 1 hour daily for 9 consecutive days; sham stress (control rats) were placed on a similar platform in a container without water.

Assessment of rat vaginal epithelial barrier permeability

After the last stress session, $0.3 \mathrm{ml}$ FITC-dextran $(10 \mathrm{mg} / \mathrm{ml} ; 1, \mathrm{MW}=4 \mathrm{kDa} ; 2$, MW $=70 \mathrm{kDa})$ was introduced into the vaginal tract under a light general anesthetization [Intraperitoneal injection with a mixture $(2.0 \mathrm{ml} / \mathrm{kg} ; 50 \mathrm{mg} / \mathrm{ml})$ of ketamine and xylazine $(0.5 \mathrm{ml} / \mathrm{kg} ; 2 \%)]$. The rats were held in a tilt position (45 degree; with the caudal end at-upside) for $30 \mathrm{~min}$ to keep the dextran inside the vaginal. The vaginal tract was washed with warm $\left(37^{\circ} \mathrm{C}\right)$ saline for 3 times to eliminate the un-absorbed dextran. The vaginal tract was then opened; the epithelia tissue was scrapped with a glass slide and processed with the procedures of protein extraction. The protein levels were determined by the Bio-Rad protein assay. The samples were analyzed by a fluorometer at $518 \mathrm{~nm}$.

Enzyme-linked immunosorbent assay (ELISA)

The serum levels of PRL were determined by ELISA with a commercial reagent kit following the manufacturer's instructions.

Cell culture and assessment of barrier function

T84 cells (a human colon epithelial cell line; between passages 20-25. Using a human colon cell line in this experiment is because T84 cell monolayers are a well-established model to test the intestinal epithelial barrier function in vitro) were purchased from ATCC (American Type Culture Collection; USA). The cells were cultured in DMEM supplemented with $10 \%$ fetal bovine serum, $100 \mathrm{U} / \mathrm{ml}$ penicillin, $0.1 \mathrm{mg} / \mathrm{ml} \mathrm{strep-}$ tomycin and $2 \mathrm{mM} \mathrm{L}$-glutamine. The cells were seeded in the inserts $(0.4 \mu \mathrm{m}$ pore size, 10 -mm diameter $)$ of Transwells. The transepithelial electric resistance (TER) was measured with an Ohmmeter. After confluence (TER $\geq 1000 \Omega \cdot \mathrm{cm}^{2}$ ), the T84 monolayers were stimulated with PRL. The TER was recorded at $0 \mathrm{~h}$ and $24 \mathrm{~h}$ after the addition of PRL. $0.1 \mathrm{ml} /$ well FITC-dextran $(10 \mathrm{mg} / \mathrm{ml} ; 1, \mathrm{MW}=4 \mathrm{kDa} ; 2, \mathrm{MW}=70 \mathrm{kDa})$ was added to the apical chambers. Samples were taken from the basal chambers $24 \mathrm{~h}$ later and analyzed by a fluorometer at $518 \mathrm{~nm}$. The cell viability was greater than $98 \%$ as assessed by the Trypan blue exclusion assay.

\section{Real time quantitative RT-PCR (RT-qPCR)}

Total RNA was isolated from T84 cells using TRIzol reagent. Reverse transcription (RT) was performed with $50 \mathrm{ng}$ of total RNA using a reverse transcription kit. Reactions included $10 \mu \mathrm{L}$ of SYBR Green Master Mix, $5 \mu \mathrm{L}$ of cDNA, and $0.2 \mu \mathrm{L}$ of primer set for performing real-time PCR with a Real Time PCR device (MiniOpticon, Bio-Rad, Shanghai, China). The oligonucleotide primers of occludin used for the amplification included: Forward, tttggaccataaccccggaa; reverse, atcgtctggggtgtgaaagt. The $\beta$-actin gene was used as endogenous control with the primers of forward, caaccttcttgcagctcctc; reverse, atacccaccatcacaccctg. A threshold cycle (Ct) was observed in the exponential phase of amplification, the relative mRNA expression level was determined by calculating the $\Delta \Delta \mathrm{Ct}$ values, and the fold change was expressed as $2^{-\Delta \Delta c t}$.

\section{Western blot analysis}

Proteins were extracted from the T84 cells; the content was determined using the Bradford protein assay. Equal amounts of protein extracts were resolved by SDS-PAGE (sodium dodecyl sulfate-polyacrylamide gel) electrophoresis. Samples were electroblotted onto a PVDF membrane. The membranes were incubated with 3\% non-fat milk in TBST (Tris-buffered saline Tween 20) with the primary antibodies (1:1,000) overnight at $4^{\circ} \mathrm{C}$, followed by incubation with the second antibodies (peroxidase-conjugated, 1:2,500) to reveal immunocomplexes by enhanced chemiluminescence. The results were photographed with a KODAK Image Station 4000Pro (KODAK, Shanghai, China). The integrated density of the blots was determined with the software of ImageJ. 


\section{Cellular Physiology Cell Physiol Biochem 2015;37:153-161 \begin{tabular}{l|l|l}
\hline DOI: 10.1159/000430341 & (C) 2015 S. Karger AG, Basel
\end{tabular} \begin{tabular}{l|l|} 
and Biochemistry Published online: August 17, 2015 & www.karger.com/cpb \\
\cline { 1 - 2 }
\end{tabular} \\ Li/Liu/Yu: PRL Compromises Vaginal Epithelial Barrier Function}

Chromatin immunoprecipitation (ChIP).

ChIP assays were performed using a ChIP kit (Sigma Aldrich) according to manufacturer's instructions. Briefly, $3 \times 10^{7}$ cells were cross-linked with $1 \%$ formaldehyde for $10 \mathrm{~min}$; the cells were then lysed in a cell lysis buffer containing protease inhibitor. The samples were precleared with protein A/G agarose/ salmon sperm DNA slurry, and immunoprecipitation analysis was performed at $4{ }^{\circ} \mathrm{C}$ overnight using an anti-STAT3 antibody or normal mouse IgG (using as a negative control) overnight at $4{ }^{\circ} \mathrm{C}$ with mild agitation. The antibody/chromatin complexes were collected by incubation with protein A/G agarose and analyzed by PCR. For the STAT3 binding sites, the primers included: Forward, AGGAGTCTTTCGTTGGAGCA; reverse, CTGCTTCGGATGGAACCTTG [16]. The DNA purified from the sonicated nuclear lysate was analyzed by realtime PCR using the same primer sets. The resulting data were used as an input control. Expression of a target DNA sequence was normalized to the input DNA.

\section{Methylation-specific PCR}

The genomic DNA was isolated from T84 cells using a phenol-chloroform extraction followed by ethanol precipitation. The DNA ( $1 \mu \mathrm{g}$ ) was treated with bisulphite using EZ DNA Methylation-Gold TM Kit (Zymo Research, Irvine, NY, USA) following the manufacturer's instructions. The modified DNA was subjected to qPCR. A pair of primers was designed to amplify the unmethylated alleles. The primers included forward, ttaaggttttatttgaagtaggtgg and reverse, caatattacaacccaaaaaacaaa.

Overexpression of occludin in T84 cells

The plasmid pcDNA-vector and pcDNA-occludin were provided by GenScript (Nanjing, China). These plasmids were transfected into cells with Lipofectamine 2000 transfection reagent (Invitrogen) according to the manufacturer's instructions. The expression of occludin in T84 cells was assessed by RT-qPCR and Western blotting.

\section{Statistics}

The data are presented as mean \pm SD and processed in Microsoft Excel. The differences between groups were determined by Student $t$ test or ANOVA if more than two groups. A $p<0.05$ was set as a significant criterion.

\section{Results}

Chronic stress induces PRL in the vaginal epithelia

Based on the reports that prolactin (PRL) plays a role in the epithelial barrier dysfunction [17], psychological stress can increase the release of PRL [12], we inferred that chronic stress might be associated with vaginal epithelial barrier dysfunction. To this end, we carried out a rat model study, in which rats were treated with a 9-day chronic stress. We found that, after the stress, PRL was detected in the sera (Fig. 1A) and vaginal epithelia (Fig. 1B-C) after stress, which was also in a stress time-dependent manner. The levels of PRL were not changed in the vaginal epithelium of the rats treated with sham stress. The results indicate that the stress increases the PRL release in the body, including the vaginal epithelia.

\section{Chronic stress increases rat vaginal epithelial barrier permeability}

Published data indicate that stress-induced PRL release is involved in the up regulation of epithelial barrier permeability [12], the data of Fig. 1 implicate that the stress may increase the rat vaginal epithelial barrier permeability. To test the hypothesis, we treated rats with the 9-day chronic stress. The vaginal epithelial permeability was assessed by the absorption of FITC-dextran in the vaginal epithelia. The results showed that chronic stress significantly increased the dextran-absorption in a stress time-dependent manner, which could be abolished by administration with an inhibitor of PRL, the cabergoline (Fig. 2).

\section{$P R L$ disrupts vaginal epithelial barrier integrity}

We next cultured the T84/E6E7 (T84, in short) cells into an epithelial monolayer. The T84 monolayers were exposed to PRL in the culture. The transepithelial electric resistance 

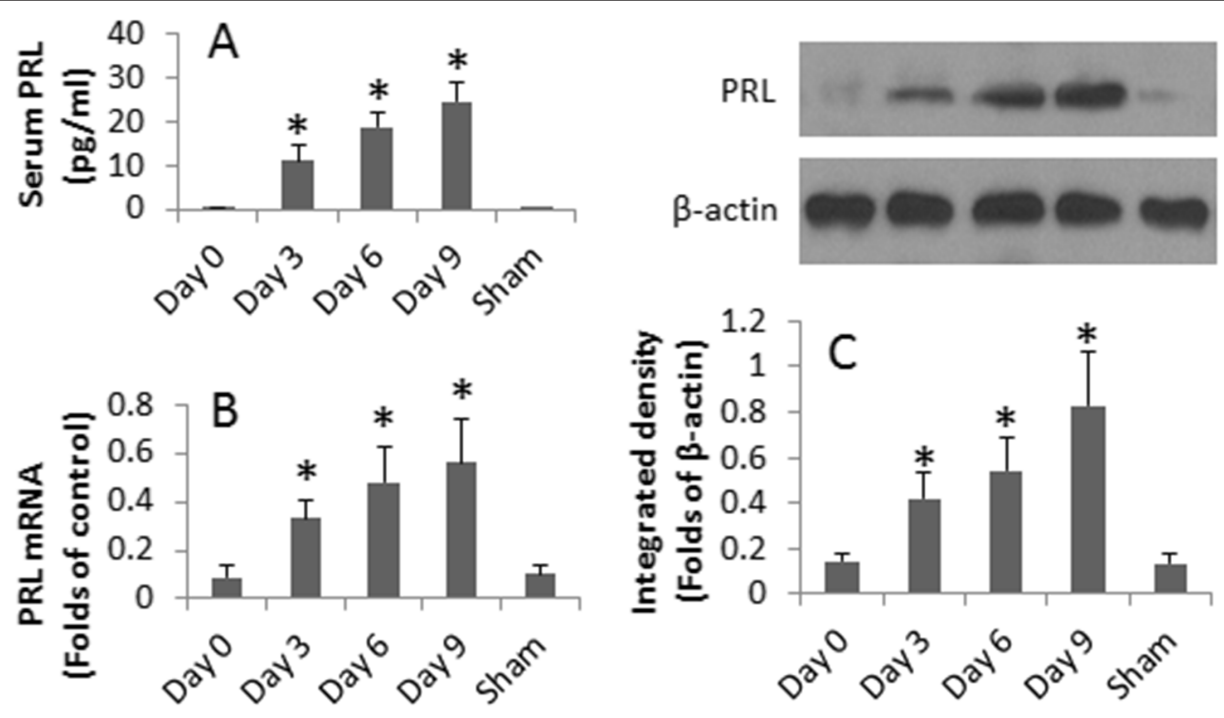

Fig. 1. Chronic stress increases PRL in the vaginal mucosa. Rats were treated with a 9-day stress. The vaginal mucosal samples and blood samples were collected after the last stress session and analyzed by RTqPCR, ELISA and Western blotting. A, the bars indicate the serum levels of PRL (by ELISA). B, the bars indicates the mRNA levels of PRL in the vaginal epithelium extracts. $C$, the Western blots indicate the protein levels of PRL in the vaginal mucosa. The bars below the blots indicate the integrated density of the Western blots. Sham: Rats were treated with sham stress for 9 days. The data of bars are presented as mean \pm SD. *, $\mathrm{p}<0.05$, compared with the group of day 0. Each group consists of 6 rats. Samples from individual rats were processed separately.
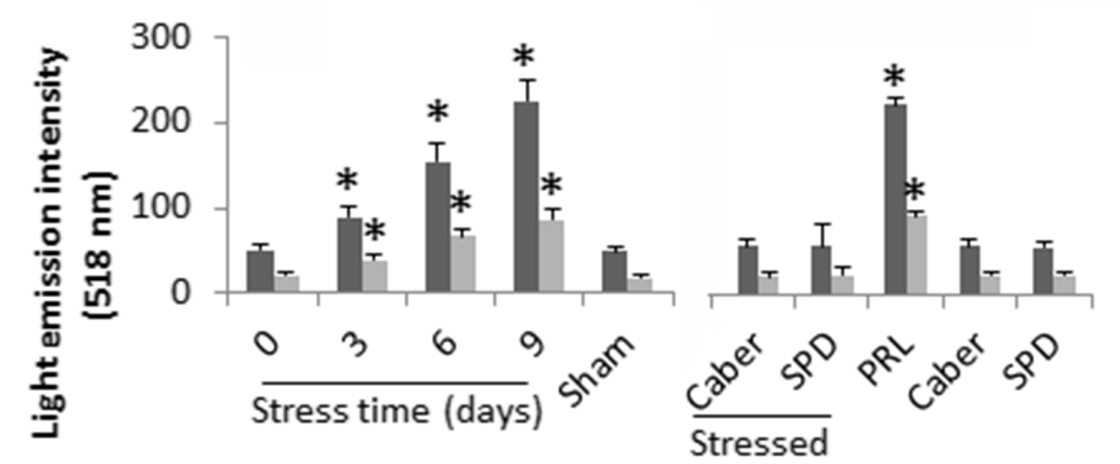

$4 \mathrm{kDa}$ $70 \mathrm{kDa}$

Fig. 2. Vaginal epithelial barrier permeability assessment. After stress session, dextran-FITC ( $0.3 \mathrm{ml} / \mathrm{rat} ; 10$ $\mathrm{mg} / \mathrm{ml}$ ) of $4 \mathrm{kDa}$ or $70 \mathrm{kDa}$ was introduced into the vagina. Thirty minutes later, the vagina was washed with saline $\left(37^{\circ} \mathrm{C}\right)$ three times. The vaginal mucosa was collected and processed with the procedures of protein extraction. The extracts were analyzed with a fluorometer at $518 \mathrm{~nm}$. A-B, the bars indicate the light emission intensity. Sham: Rats were treated with sham stress. Caber: Inhibitor of PRL (cabergoline; $500 \mu \mathrm{g} / \mathrm{kg}$; ip at $30 \mathrm{~min}$ before each stress session). SPD: A STAT3 inhibitor (Spermidine; $10 \mathrm{mg} / \mathrm{kg}$; ip $30 \mathrm{~min}$ before the stress session). The data of bars are presented as mean \pm SD. ${ }^{*}, \mathrm{p}<0.05$, compared with the group of day 0 . Each group consists of 6 rats. Samples from individual rats were processed separately.

(TER) of the monolayers was markedly decreased (Fig. 3A), and the monolayer permeability was markedly increased (Fig. 3B), in a PRL dose-dependent manner.

PRL modulates STAT3 activity in T84 cells

Previous reports indicate that PRL increases STAT3 activity [18]. Thus, we inferred that STAT3 was also involved in the compromising the vaginal epithelial barrier function. To test 

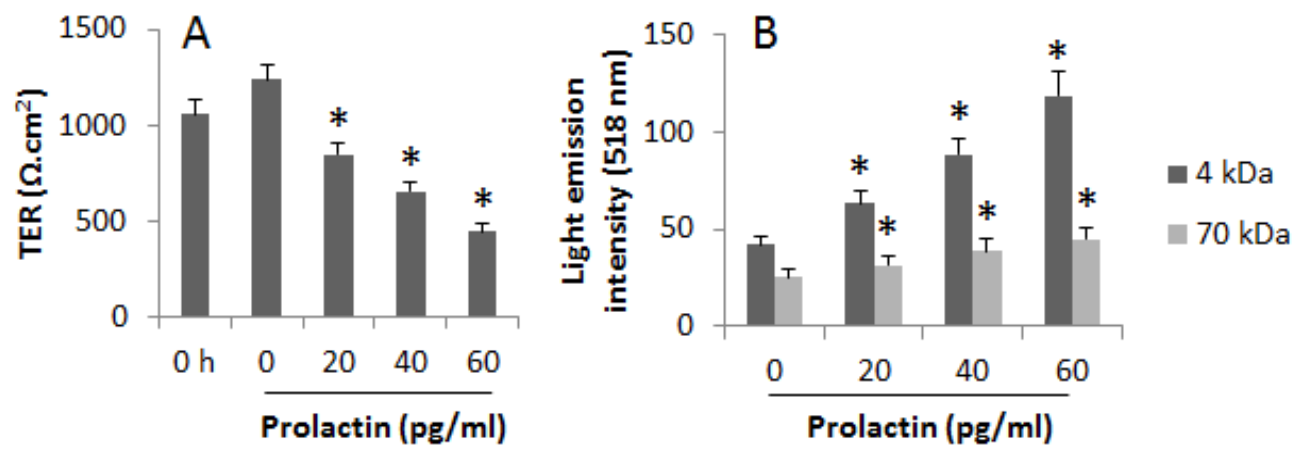

Fig. 3. PRL modulates T84 monolayer barrier function. A, T84 monolayers were exposed to PRL (denoted on the $\mathrm{X}$ axis) in the culture for $24 \mathrm{~h}$. The bars indicate the TER of the monolayers. B, dextran-FITC of $4 \mathrm{kDa}$ or $70 \mathrm{kDa}$ was added to the inserts $(10 \mathrm{mg} / \mathrm{ml})$ at $24 \mathrm{~h}$ after the addition of PRL. Samples were taken from the basal chambers $6 \mathrm{~h}$ after the addition. The bars indicate the permeability to dextran of the monolayers. The data of bars are presented as mean \pm SD. ${ }^{*}, \mathrm{p}<0.05$, compared with the group of PRL dose 0 group. The data are representatives of 3 independent experiments.

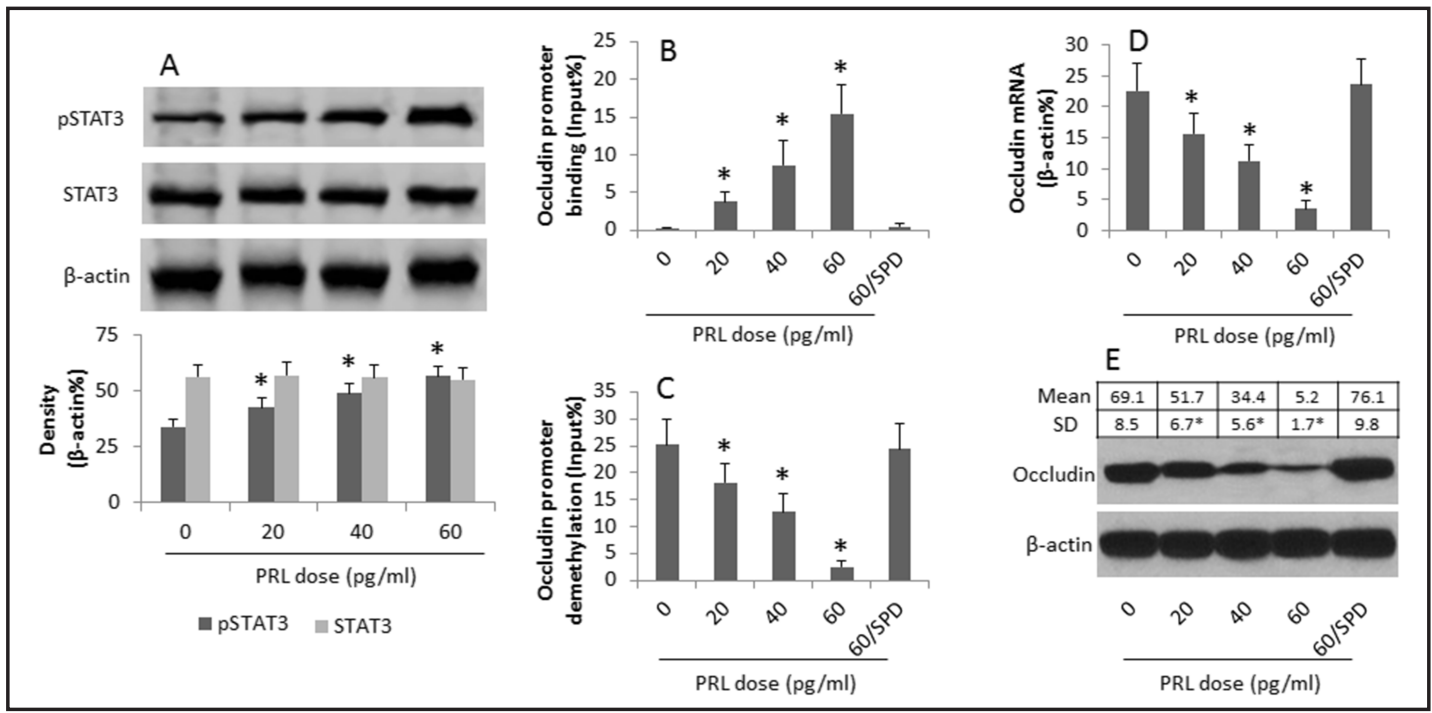

Fig. 4. PRL modulates occludin expression in T84 cells. T84 cells were exposed to PRL (the dosage is denoted in the Figure) for $48 \mathrm{~h}$. The cell extracts were analyzed. A, the Western blots indicate the protein levels of pSTAT3 and STAT3. The bars below the blots indicate the integrated density of the blots. B, the bars indicate the pSTAT3 binding rate to the occludin promoter (by ChIP). C, the bars indicate the rate of the occludin gene DNA demethylation (by methylation specific PCR). D, the bars indicate the occludin mRNA levels (by RT-qPCR). E, the Western blots indicate the occludin protein levels. The data of bars are presented as mean \pm SD. ${ }^{*}, \mathrm{p}<0.01$, compared to the group of dose 0 . The data are representatives of 3 independent experiments.

the inference, we analyzed the phosphorylation of STAT3 (pSTAT3) levels in T84 cells after exposure to PRL. Indeed, the results showed that the exposure to PRL increased the phosphorylation of STAT3 in T84 cells (Fig. 4). The data suggest that the activation of STAT3 may mediate the effect of PRL on compromising of the T84 monolayer barrier integrity. To test the inference, we added a STAT3 inhibitor (Spermidine; SPD) and PRL to the confluent T84 monolayers, which blocked the effect of PRL on inducing the monolayer barrier dysfunction (Fig. 3A-B). To enforce the results, we treated rats with the STAT3 inhibitor 30 min before the stress session; it also blocked the stress-induced vaginal epithelial barrier dysfunction (Fig. 2).

\section{KARGER}




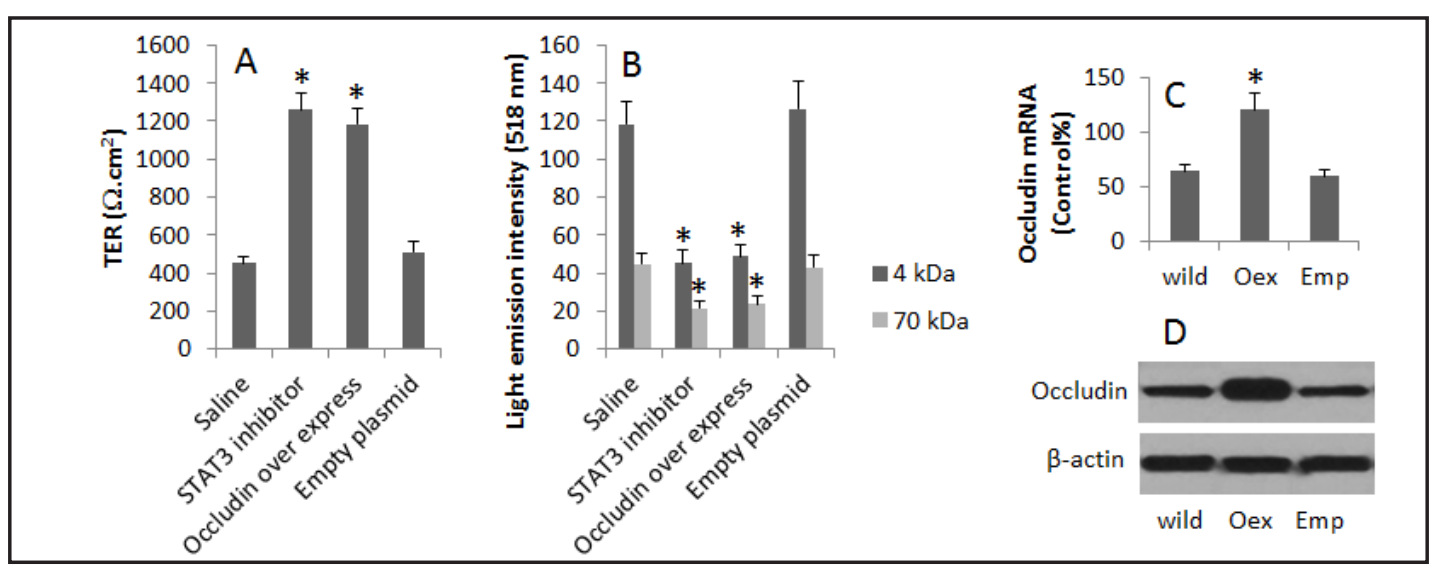

Fig. 5. PRL modulates occludin expression to affect T84 monolayer barrier function. A, T84 monolayers were exposed to PRL ( $60 \mathrm{pg} / \mathrm{ml})$ in the culture for $24 \mathrm{~h}$. The bars indicate the TER of the monolayers. B, dextran-FITC of $4 \mathrm{kDa}$ or $70 \mathrm{kDa}$ was added to the inserts $(10 \mathrm{mg} / \mathrm{ml})$ at $24 \mathrm{~h}$ after the addition of PRL. Samples were taken from the basal chambers $6 \mathrm{~h}$ after the addition. The bars indicate the permeability to dextran of the monolayers. SPD: STAT3 inhibitor $(10 \mu \mathrm{M})$. Oex: T84 cells with occludin overexpression (C; the bars indicate the mRNA levels of occludin). D, the Western blots show the protein levels of occludin. Emp: T84 cells were transfected with empty plasmids. The data of bars are presented as mean \pm SD. ${ }^{*}, \mathrm{p}<0.05$, compared with the saline group (A, B), or wild cells (C). The data are representatives of 3 independent experiments.

PRL modulates tight junction protein occludin expression in T84 cells

Occludin is an important tight junction associated protein. Published data indicate that activation of STAT3 inhibits occludin expression in epithelial cells [19]. Since PRL increases STAT3 phosphorylation in T84 cells, we infer that PRL modulates the occludin expression in T84 cells via modulating STAT3 activation. To test the hypothesis, we assessed the binding rate between pSTAT3 and the occludin promoter. The results showed that the exposure to PRL markedly increased the binding rate (Fig. 4B). The exposure to PRL also decreased the occludin gene DNA demethylation (Fig. 4C), mRNA levels (Fig. 4D) and protein levels (Fig. 4E). The data support the hypothesis that PRL inhibits occludin expression in T84 cells. To enforce the results, we carried out separate experiments, in which we over expressed occludin in T84 cells. The cells were cultured into monolayers and exposed to PRL in a Transwell system. The results showed that the overexpression of occludin significantly attenuated the PRL-induced TER drop and permeability increase (Fig. 5).

\section{Discussion}

The pathogenesis of epithelial barrier disruption plays a critical role in a large number of mucosal disorders. Thus, to elucidate the causative factors of epithelial barrier dysfunction is of significance. The present data show that stress can compromise the vaginal epithelial barrier integrity, induce hyperpermeability to macromolecular substances via repressing the expression of occludin, one of the tight junction associated proteins.

The primary role of PRL is to enable female mammals to produce milk [20]. Other functions of PRL also have been discovered. Patil et al report that PRL influences neuronal functions via activation of certain neurons, resulting in $\mathrm{Ca}(2+)$ influx and/or electrical firing with subsequent release of neurotransmitters [21]. It is suggested that PRL serves a critical role in breast cancer progression via activation of its cognate receptor [22]. Our data reveal another functional aspect that PRL can compromise the vaginal epithelial barrier integrity. The results suggest that PRL is not only produced by the pituitary gland, rat vaginal epithelial cells and human vaginal epithelial cell lines also can produce PRL. Supporting results are published. Langan et al report that skin cells also produce PRL [23]. 


\section{Cellular Physiology Cell Physiol Biochem 2015;37:153-161 \begin{tabular}{l|l} 
DOI: 10.1159/000430341 & (c) 2015 S. Karger AG, Basel
\end{tabular} and Biochemistry

Epithelial barrier dysfunction is associated with a large number of diseases. Santos et al report that cold stress induces human intestinal epithelial barrier hyperpermeability [24]. Yang et al reveal that stress induces corticotrophin releasing factor to release and compromises intestinal epithelial barrier dysfunction [15]. Our data are in line with those previous studies by showing that stress induces epithelial barrier dysfunction. The novel aspect of our study is that stress increases PRL levels in the peripheral system, such as in the serum and in the vaginal epithelia. The increase in PRL levels and the increase in vaginal epithelial barrier permeability are in parallel. It is not a coincident event since the hyperpermeability of the vaginal epithelial barrier can be blocked by the presence of a PRL inhibitor.

Although the epithelial tight junctions consist of several proteins, the abnormality of the proteins may result in the epithelial barrier dysfunction. Nassour et al indicate that loss of claudin-1 increases epithelial barrier permeability [25]. Lei et al show evidence that a decrease in the expression of the TJ protein, ZO-1, compromises the epithelial barrier function [26]. Our data are in line with those studies by showing that the inhibition of occludin by PRL induces markedly hyperpermeability in the Vk1 monolayer barrier, which can be prevented by the over expression of occludin in the Vk1 cells. These data suggest that even one of the proteins of the tight junction can cause the barrier dysfunction.

PRL can induce STAT3 phosphorylation [27]. Our data are in line with the reports by showing that exposure to PRL significantly increases STAT3 phosphorylation in vaginal epithelial cells. STAT3 is a transcription factor that is involved in the gene transcription of a number of molecules, some of which contribute to initiation of inflammation, such as Martinez-Neri et al suggest that PRL might be modulating the pro-inflammatory response against mycobacterial antigens through the MAPK pathway [27]. Neradugomma et al report that PRL activates STAT3 to promote carcinogenesis [28]. The present data provide a novel aspect that PRL activates STAT3 to compromise the vaginal epithelial barrier function via repressing occludin expression.

In summary, the present data indicate that stress-derived PRL can induce vaginal epithelial barrier dysfunction, which can be abolished by blocking PRL, or regulate some components, such as STAT3.

\section{Disclosure Statement}

This study was supported by the International Cooperation Project (2013DFB30130) from the Family Planning Foundation. Beijing, China

\section{References}

1 Wira CR, Grant-Tschudy KS, Crane-Godreau MA: Epithelial cells in the female reproductive tract: A central role as sentinels of immune protection. Am J Reproduct Immunol 2005;53:65-76.

2 van der Bijl P, van Eyk AD: Human vaginal mucosa as a model of buccal mucosa for in vitro permeability studies: An overview. Curr Drug Deliv 2004;1:129-135.

3 Lambrecht BN, Hammad H: Allergens and the airway epithelium response: Gateway to allergic sensitization. J Allergy Clin Immunol 2014;134:499-507.

4 Lee SH: Intestinal permeability regulation by tight junction: Implication on inflammatory bowel diseases. Intest Res 2015;13:11-18.

5 Dusio GF, Cardani D, Zanobbio L, Mantovani M, Luchini P, Battini L, Galli V, Diana A, Balsari A, Rumio C: Stimulation of tlrs by lmw-ha induces self-defense mechanisms in vaginal epithelium. Immunol Cell Biol 2011;89:630-639.

6 Franke WW, Pape UF: Diverse types of junctions containing tight junction proteins in stratified mammalian epithelia. Ann N Y Acad Sci 2012;1257:152-157.

7 Price DB, Ackland ML, Burks W, Knight MI, Suphioglu C: Peanut allergens alter intestinal barrier permeability and tight junction localisation in caco-2 cell cultures. Cell Physiol Biochem 2014;33:17581777. 


\section{Cellular Physiology Cell Physiol Biochem 2015;37:153-161 \begin{tabular}{l|l|l} 
DOI: 10.1159/000430341 & (C) 2015 S. Karger AG, Basel
\end{tabular} and Biochemistry Published online: August 17, 2015

8 Sanders DS: Mucosal integrity and barrier function in the pathogenesis of early lesions in crohn's disease. J Clin Pathol 2005;58:568-572.

9 Wang P, Qi H, Sun C, He W, Chen G, Li L, Wang F: Overexpression of hypoxia-inducible factor-1alpha exacerbates endothelial barrier dysfunction induced by hypoxia. Cell Physiol Biochem 2013;32:859-870.

10 Bole-Feysot C, Goffin V, Edery M, Binart N, Kelly PA: Prolactin (prl) and its receptor: Actions, signal transduction pathways and phenotypes observed in prl receptor knockout mice. Endocr Rev 1998;19:225268.

11 Mori R, Nagahama Y, Bern HA, Young PN: Ultrastructural changes in vaginal epithelium of mice neonatally treated with estrogen and prolactin. Anat Rec 1974;179:225-240.

12 Wu W, Sun M, Zhang HP, Chen T, Wu R, Liu C, Yang G, Geng XR, Feng BS, Liu Z, Liu Z, Yang PC: Prolactin mediates psychological stress-induced dysfunction of regulatory t cells to facilitate intestinal inflammation. Gut 2014;63:1883-1892.

13 Pierce AN, Ryals JM, Wang R, Christianson JA: Vaginal hypersensitivity and hypothalamic-pituitary-adrenal axis dysfunction as a result of neonatal maternal separation in female mice. Neuroscience 2014;263:216230.

14 Milad MR, Igoe SA, Lebron-Milad K, Novales JE. Estrous cycle phase and gonadal hormones influence conditioned fear extinction. Neuroscience. 2009;164: 887-95.

15 Yang PC, Jury J, Soderholm JD, Sherman PM, McKay DM, Perdue MH: Chronic psychological stress in rats induces intestinal sensitization to luminal antigens. Am J Pathol 2006;168:104-114.

16 Mankertz J, Tavalali S, Schmitz H, Mankertz A, Riecken EO, Fromm M, Schulzke JD: Expression from the human occludin promoter is affected by tumor necrosis factor alpha and interferon gamma. J Cell Sci 2000;113:2085-2090.

17 Peixoto EB, Collares-Buzato CB: Modulation of the epithelial barrier by dexamethasone and prolactin in cultured madin-darby canine kidney (mdck) cells. Cell Biol Int 2006;30:101-113.

18 Yang X, Friedl A: A positive feedback loop between prolactin and stat5 promotes angiogenesis. Adv Exp Med Biol 2015;846:265-280.

19 Penrose HM, Marchelletta RR, Krishnan M, McCole DF: Spermidine stimulates t cell protein-tyrosine phosphatase-mediated protection of intestinal epithelial barrier function. J Biol Chem 2013;288:3265132662.

20 Need EF, Atashgaran V, Ingman WV, Dasari P: Hormonal regulation of the immune microenvironment in the mammary gland. J Mammary Gland Biol Neoplasia 2014;19:229-239.

21 Patil MJ, Henry MA, Akopian AN: Prolactin receptor in regulation of neuronal excitability and channels. Channels 2014;8:193-202.

22 Kavarthapu R, Tsai Morris CH, Dufau ML: Prolactin induces up-regulation of its cognate receptor in breast cancer cells via transcriptional activation of its generic promoter by cross-talk between eralpha and stat5. Oncotarget 2014;5:9079-9091.

23 Langan EA, Vidali S, Pigat N, Funk W, Lisztes E, Biro T, Goffin V, Griffiths CE, Paus R: Tumour necrosis factor alpha, interferon gamma and substance $\mathrm{p}$ are novel modulators of extrapituitary prolactin expression in human skin. PloS one 2013;8:e60819.

24 Santos J, Saperas E, Nogueiras C, Mourelle M, Antolin M, Cadahia A, Malagelada JR: Release of mast cell mediators into the jejunum by cold pain stress in humans. Gastroenterology 1998;114:640-648.

25 Nassour H, Dubreuil JD: Escherichia coli stb enterotoxin dislodges claudin-1 from epithelial tight junctions. PloS one 2014;9:e113273.

26 Lei Q, Qiang F, Chao D, Di W, Guoqian Z, Bo Y, Lina Y: Amelioration of hypoxia and lps-induced intestinal epithelial barrier dysfunction by emodin through the suppression of the nf-kappab and hif-1alpha signaling pathways. Int J Mol Med 2014;34:1629-1639.

27 Martinez-Neri PA, Lopez-Rincon G, Mancilla-Jimenez R, Del Toro-Arreola S, Munoz-Valle JF, Fafutis-Morris M, Bueno-Topete MR, Estrada-Chavez C, Pereira-Suarez AL: Prolactin modulates cytokine production induced by culture filtrate proteins of $\mathrm{m}$. Bovis through different signaling mechanisms in thp1 cells. Cytokine 2015;71:38-44.

28 Neradugomma NK, Subramaniam D, Tawfik OW, Goffin V, Kumar TR, Jensen RA, Anant S: Prolactin signaling enhances colon cancer stemness by modulating notch signaling in a jak2-stat3/erk manner. Carcinogenesis 2014;35:795-806. 